\title{
Relevance of Lipid-Based Products in the Management of Dry Eye Disease
}

\author{
Jean-Sébastien Garrigue,' Mourad Amrane,' Marie-Odile Faure, \\ Juha M. Holopainen, ${ }^{3, \dagger}$ and Louis Tong ${ }^{4-7}$
}

\begin{abstract}
Components of the ocular surface synergistically contribute to maintaining and protecting a smooth refractive layer to facilitate the optimal transmission of light. At the air-water interface, the tear film lipid layer (TFLL), a mixture of lipids and proteins, plays a key role in tear surface tension and is important for the physiological hydration of the ocular surface and for ocular homeostasis. Alterations in tear fluid rheology, differences in lipid composition, or downregulation of specific tear proteins are found in most types of ocular surface disease, including dry eye disease (DED). Artificial tears have long been a first line of treatment in DED and aim to replace or supplement tears. More recently, lipid-containing eye drops have been developed to more closely mimic the combination of aqueous and lipid layers of the TFLL. Over the last 2 decades, our understanding of the nature and importance of lipids in the tear film in health and disease has increased substantially. The aim of this article is to provide a brief overview of our current understanding of tear film properties and review the effectiveness of lipid-based products in the treatment of DED. Liposome lid sprays, emulsion eye drops, and other lipid-containing formulations are discussed.
\end{abstract}

Keywords: tear film, lipid layer, liposome, emulsion, ocular surface disease

\section{Introduction}

$\mathbf{O}$ VER THE LAST 2 DECADES, our understanding of the nature and importance of lipids in the tear film in health and disease has increased substantially. In this review, we review the effectiveness of lipid-based products in the treatment of dry eye disease (DED), including liposome lid sprays, emulsion eye drops, and other lipid-containing formulations.

The ocular surface is a critical element of vision that includes the cornea, conjunctiva, lacrimal gland, accessory lacrimal glands, meibomian glands, tears, connective tissues, eyelashes and their associated glands of Moll and Zeis, and the nasolacrimal duct. ${ }^{1}$ Each of these elements has a specific role; is controlled by nervous, endocrine, circulatory, and inflammatory systems; and synergistically contributes to maintaining and protecting the smooth refractive surface and transparency of the cornea for optimal transmission of light. ${ }^{1,2}$ Lacrimal glands, accessory lacrimal glands, and meibomian glands secrete aqueous fluid, proteins, and lipids to form the tear film that hydrates the cornea. ${ }^{1,3}$

The tear film was first described by Wolff et al. as 3 distinct layers: the outer lipid layer, the middle aqueous layer, and the inner mucin layer, which interacts with the corneal epithelial surface. ${ }^{4,5}$ The aqueous layer contains electrolytes, proteins/peptides, and small-molecule metabolites. ${ }^{6}$ Mucins present in the deepest layer of the tear film, such as glycocalyx, mucin, and membrane-associated mucins, are released by goblet cells and maintain the wettability of the corneal surface. ${ }^{5}$ To date, several hundred tear proteins have been identified, including lysozyme and lactoferrin, which have

\footnotetext{
${ }^{1}$ Santen SAS, R\&D Innovation Center, Evry, France.

${ }^{2}$ Scientific Consulting For You, Paris, France.

${ }^{3}$ Helsinki Eye Lab, Ophthalmology, Helsinki University Hospital, University of Helsinki, Helsinki, Finland.

${ }_{5}^{4}$ Singapore Eye Research Institute, Singapore.

${ }^{5}$ Yong Loo Lin School of Medicine, National University of Singapore, Singapore.

${ }^{6}$ Duke-NUS Medical School, Singapore.

${ }^{7}$ Singapore National Eye Center, Singapore.

†Deceased.
}

(C) Jean-Sébastien Garrigue et al., 2017; Published by Mary Ann Liebert, Inc. This is an Open Access article distributed under the terms of the Creative Commons Attribution License, which permits unrestricted use, distribution, and reproduction in any medium, provided the original work is properly cited. 
antibacterial properties to protect the ocular surface from pathogens, ${ }^{3,6}$ and lipocalin, which can intercalate with tear lipids to form an additional biphasic lipid layer not described in Wolff's original 3-layer model. ${ }^{7,8}$

At the air-water interface, the outer layer, also called the tear film lipid layer (TFLL), is primarily composed of lipids that prevent water evaporation and ocular surface dewetting and provide a smooth optical surface for the cornea.,9-11 More recently, additional roles of the TFLL have been described, including maintenance of ocular homeostasis, optimization of tear spreading patterns, direction of aqueous flow to the puncta, and prevention of film overflow during blinking. ${ }^{11,12}$ Lipids are released by the meibomian glands located in the eyelids, both during blinking and under the control of vasoactive intestinal polypeptide; the composition of these lipids may be affected by ATP stimulation of purinergic receptors expressed on the meibomian glands. ${ }^{7}$

The TFLL is composed primarily of nonpolar lipids (wax esters and cholesterol esters), but small amounts of polar lipids (phospholipids) have also been found in the TFLL from human and laboratory animals. The hydrophilic polar lipids act as an interface between the aqueous layer and the nonpolar lipid surface layer. ${ }^{7,13,14}$ The wax ester in the nonpolar surface layer is thought to delay evaporation, ${ }^{15,16}$ but its exact role is controversial, as recent evaporation studies and rheology have questioned the ability of wax esters to prevent tear evaporation in vivo. ${ }^{15,17}$

The TFLL also includes fatty acids and fatty alcohols (including acetic acid) that act as surfactants to stabilize the lipid-water mixture. ${ }^{7,11}$ The fatty acid-lysophospholipid balance is governed by the amounts of cholesterol and/or epicholesterol, glycerols, and lysophospholipids in the TFLL. More recently, amphiphilic lipids, such as cholesteryl sulfate, $O$-acyl- $\omega$-hydroxy fatty acids, various sphingolipids, and phospholipids, were found in the human TFLL. ${ }^{18}$ The lipid and protein components of the TFLL play a key role in tear surface tension and are important for the physiological hydration of the ocular surface and ocular homeostasis. $5,11,12,14$

\section{Pathophysiology and Treatment of Ocular Surface Disease}

The ocular surface is affected by medications (eg, antiglaucoma drugs), contact lens wear, and ocular surface diseases $^{6,19}$ such as DED, blepharitis, and ocular allergies. DED can be classified into aqueous tear deficient, evaporative, and mixed forms depending on its etiology. ${ }^{20}$ Evaporative DED, typically caused by meibomian gland dysfunction (MGD), is attributed to a qualitative and/or quantitative defect of the lipid layer that leads to tear film instability. ${ }^{20}$ Patients lacking a visible lipid layer, or those with a nonconfluent TFLL, have a 4-fold higher rate of tear film evaporation than those with a continuous lipid layer regardless of lipid layer thickness. ${ }^{21}$ Alterations in tear fluid rheology or lipid composition or the downregulation of specific tear proteins are found in most types of DED; for example, alterations in the phospholipid content, potentially due to bacterial lipase-mediated hydrolysis of phospholipids into lysophospholipids, can lead to $\operatorname{DED}^{7,11,18,22}$

The first line of therapy for DED is aimed at relieving patient symptoms. ${ }^{23}$ In MGD, gland obstructions can be cleared by warm compresses and self-administered lid massages, by thermal pulsation treatment (eg, LipiFlow) or by intraductal meibomian gland probing. ${ }^{24,25}$ In DED, artificial tears are used to replace or supplement tears. ${ }^{26}$

Lipid-containing eye drops have been proposed as a step closer to natural tears because they more closely mimic the aqueous and lipid layers. ${ }^{27}$ Such lipid-based agents would be expected to benefit patients with DED (particularly the evaporative form of DED), as well as related ocular surface diseases (eg, diseases of allergic/infectious origin such as allergic rhinoconjunctivitis, or other conditions such as contact lens discomfort). In tear film-oriented therapy (TFOT), treatment is tailored based on analysis of tear film dynamics, which includes identification of the damaged ocular surface or tear film component in the patient with DED. ${ }^{28}$ Because the TFOT tailors treatment to a specific component of DED pathophysiology, TFOT is becoming a recommended treatment paradigm in Japan. ${ }^{28}$

Additionally, topical therapeutic options are available to individually treat each layer of the ocular surface in patients with DED. Randomized clinical trials of water-based eye drops containing sodium hyaluronate, carboxymethylcellulose, or carbomers have demonstrated improvements in DED symptoms, corneal wound healing, tear osmolarity, and tear film break-up time. ${ }^{29-32}$ However, as the lacrimal fluid also contains a combination of lipids, and given that changes in tear lipid composition can lead to DED, lipid-containing eye drops have emerged as an alternative therapy to waterbased-only artificial tears. ${ }^{20,22,33}$

Lipid-based products are designed to mimic the tear film and provide long-lasting lubrication to the eye surface, but it remains uncertain if they can fully replenish the TFLL. ${ }^{15,22}$

A recent publication by McCann et al. reported that lipidbased eye drops decreased tear film osmolarity and improved tear film stability and corneal staining more effectively than water-based eye drops containing sodium hyaluronate and hydroxypropyl methylcellulose in patients with mild-tomoderate evaporative DED. ${ }^{34}$ Furthermore, a systematic literature review of randomized controlled studies revealed strong clinical evidence for the effective use of lipidcontaining lubricants in the treatment of DED. ${ }^{35}$ Of note, the U.S. Food and Drug Administration Code of Federal Regulations Title 21 part 349 recommends that lipids can be used as "emollients" (or "lubricants") in ophthalmic products (eg, lanolin, light mineral oil, mineral oil, paraffin, petrolatum, white ointment, white wax, and yellow wax) indicated for "the temporary relief of burning and irritation due to dryness of the eye" or "the use as a lubricant to prevent further irritation or to relieve dryness of the eye.",36

\section{Lipid-Based Therapies}

\section{Liposomes}

Liposomes are bilayered lipid vesicles, structurally classified as small unilamellar or multilamellar, with a particle size of $10 \mathrm{~nm}$ to $1 \mu \mathrm{m}$, although they can sometimes be larger (Fig. 1, 1a, b). ${ }^{37}$ Biodegradable and biocompatible in nature, liposomes are mainly composed of phosphatidylcholines (phospholipids) and other constituents such as cholesterol and lipid-conjugated polymers. For therapeutic use they are prepared by thin-film hydration methods followed by 5-cycle sonication, which results in a more uniform particle size, ranging from 0.1 to $1 \mu \mathrm{m}$ in diameter, that is ideal for drug loading. ${ }^{37-39}$ 


\section{Liposomes}

a

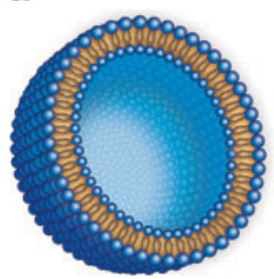

2. Emulsions

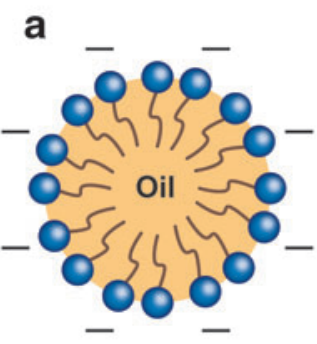

\section{Others}

a

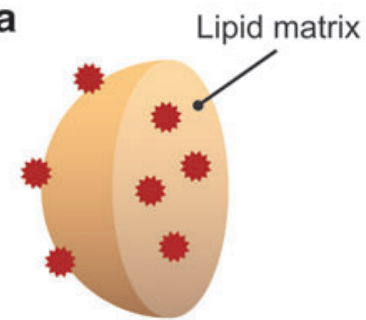

b
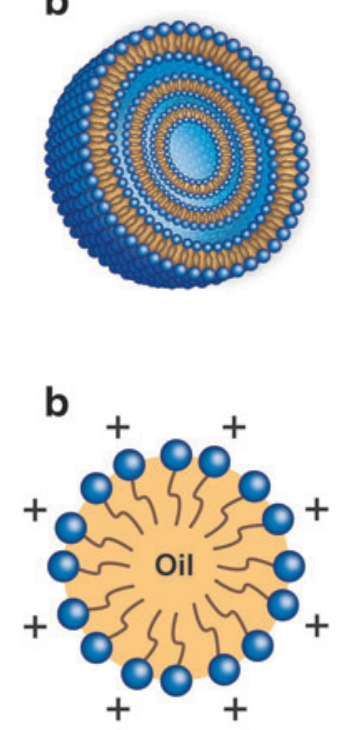

b

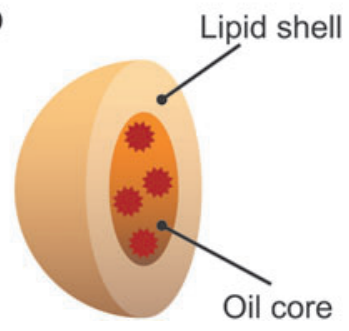

FIG. 1. Schematic representations of various lipid-based products, including unilamellar liposomes (1a), multilamellar liposomes (1b), anionic emulsions (2a), cationic emulsions (2b), SLNs (3a), NLCs (3b). SLN, solid lipid nanoparticle; NLC, nanostructured lipid carrier.

Liposomal formulations were first proposed as drug delivery vehicles in ophthalmology to enhance ocular drug penetration. Drug-loaded liposomal eye drops (eg, ciprofloxacin, acetazolamide, and tacrolimus) have been tested over the last decade to treat various ocular disorders of both the anterior and posterior segments, including infections, DED, corneal transplant rejection, glaucoma, and uveitis. ${ }^{37,40}$ In addition, nondrug-loaded liposomal lid sprays were more recently introduced for the treatment of DED with the aim of renewing the TFLL. ${ }^{40-42}$

Several products in this category, such as Tears Again ${ }^{\circledR}$ (Optima Pharmazeutische $\mathrm{GmbH}$; also marketed as Optrex ActiMist ${ }^{\circledR}$ and Eye Logic Liposomal Spray ${ }^{\circledR}$ ), Clarimist ${ }^{\circledR}$, and Vyseo ${ }^{\circledR}$ Sensitive are made of soy lecithin, which is mainly composed of the phospholipid phosphatidylcholine. ${ }^{8}$ Other components include lipophilic vitamins with potential ocularprotective properties (eg, vitamins A and E), ethanol, water, and sodium chloride. Liposomal sprays are simply applied onto the outside of the lids, and the polar phospholipids diffuse from the lid surface to the tear film and thus supplement the TFLL. This provides lubrication, helps prevent tear film evaporation, and alleviates DED symptoms. ${ }^{37,42}$

The tolerability of liposomal preparations is dictated by their surface tension, $\mathrm{pH}$, osmolarity, and viscosity. ${ }^{38} \mathrm{In}$ one study, a nondrug-loaded liposomal formulation containing phosphatidylcholine, cholesterol, and vitamin E achieved values for each of these parameters close to the physiological range (surface tension $\approx 30 \mathrm{mN} / \mathrm{m}, \mathrm{pH}$ $6.45 \pm 0.09$, osmolarity $289.43 \pm 3.28 \mathrm{mOsm}$, and viscosity $1.82 \pm 0.02 \mathrm{mPa} \bullet \mathrm{s}$ ) and was well tolerated in a rabbit model when administered every 30 min for $6 \mathrm{~h}$ (Table 1). ${ }^{38}$ The formulation induced minimal corneal and conjunctival cytotoxicity, with a cell viability greater than $95 \%$ after 15 min of exposure. ${ }^{38}$ In a rabbit model of dry eye treated with liposome-encapsulated tetracycline, tear break-up time and Schirmer's test values were significantly improved and associated with a restoration of corneal and conjunctival cytological architecture after daily liposome administration for 7 days. ${ }^{43}$

Drug-loaded liposomes exhibit improved tolerance, drug delivery and penetration, and corneal healing in comparison with other ophthalmic drug delivery vehicles typically used in rabbit models. ${ }^{44-46}$ Chitosan-coated liposomes have been developed to further enhance drug permeation and prolong drug retention rates. These benefits may be attributable in part to the positive charge of the chitosan molecules, which can bind to the negatively charged mucus film and lipid membrane of epithelium cells. Chitosan-coated liposomes are well tolerated in vivo in rabbits and in vitro in rabbit conjunctival epithelial cells. ${ }^{47}$

Nondrug-loaded liposomes also demonstrate improved clinical efficacy (Table 2). A multicenter, double-masked clinical study showed that Optrex ActiMist, also marketed as Tears Again and Eye Logic Liposomal Spray, significantly improved DED symptoms and tear film stability, which is essential for limiting the evaporation of the TFLL. ${ }^{9,48}$ The delivery of phospholipid liposomes to the tear film by applying a liposomal spray (Tears Again) to the surface of the closed eyelid has been shown to improve ocular comfort, lipid layer thickness, and tear film stability in healthy patients versus a saline spray. ${ }^{42}$ Ocular comfort scores also improved with the same product, as observed in a randomized clinical study of healthy and self-diagnosed dry eye patients using the Chalmers 5-item questionnaire; a similar reduction in the Strehl ratio of higher-order aberrations was observed in both populations. ${ }^{49}$

In an open-label, observational study in patients with seasonal allergic rhinoconjunctivitis, Tears Again in combination with a liposomal nasal spray containing dexpanthenol (LipoNasal ${ }^{\circledR}$ ) demonstrated noninferior efficacy when compared with the standard cromoglycate therapy. Liposomal spray treatment was associated with a favorable tolerability profile in terms of eye irritation and vision disturbances over a 7-day treatment period (2-3 times per eye per day). ${ }^{41}$

The liposomal treatment Lacrisek $^{\circledR}$ ofta mono (Bios Italia), which incorporates hydrogenated phospholipids, vitamin A palmitate, and vitamin E, was compared with Artelac ${ }^{\circledR}$ Rebalance, a water-based tear substitute containing polyethylene glycol and hyaluronic acid, in a single-instillation study of patients with evaporative dry eye. Improvements in interblink interval, tear break-up time (TBUT), and tear film evaporation time were superior for Lacrisek ofta mono from $10 \mathrm{~min}$ after instillation to the end of the 60-min assessment period. ${ }^{50}$ This preclinical and clinical evidence demonstrates that liposomal eye drops and sprays are well tolerated and efficacious in improving DED symptoms. 


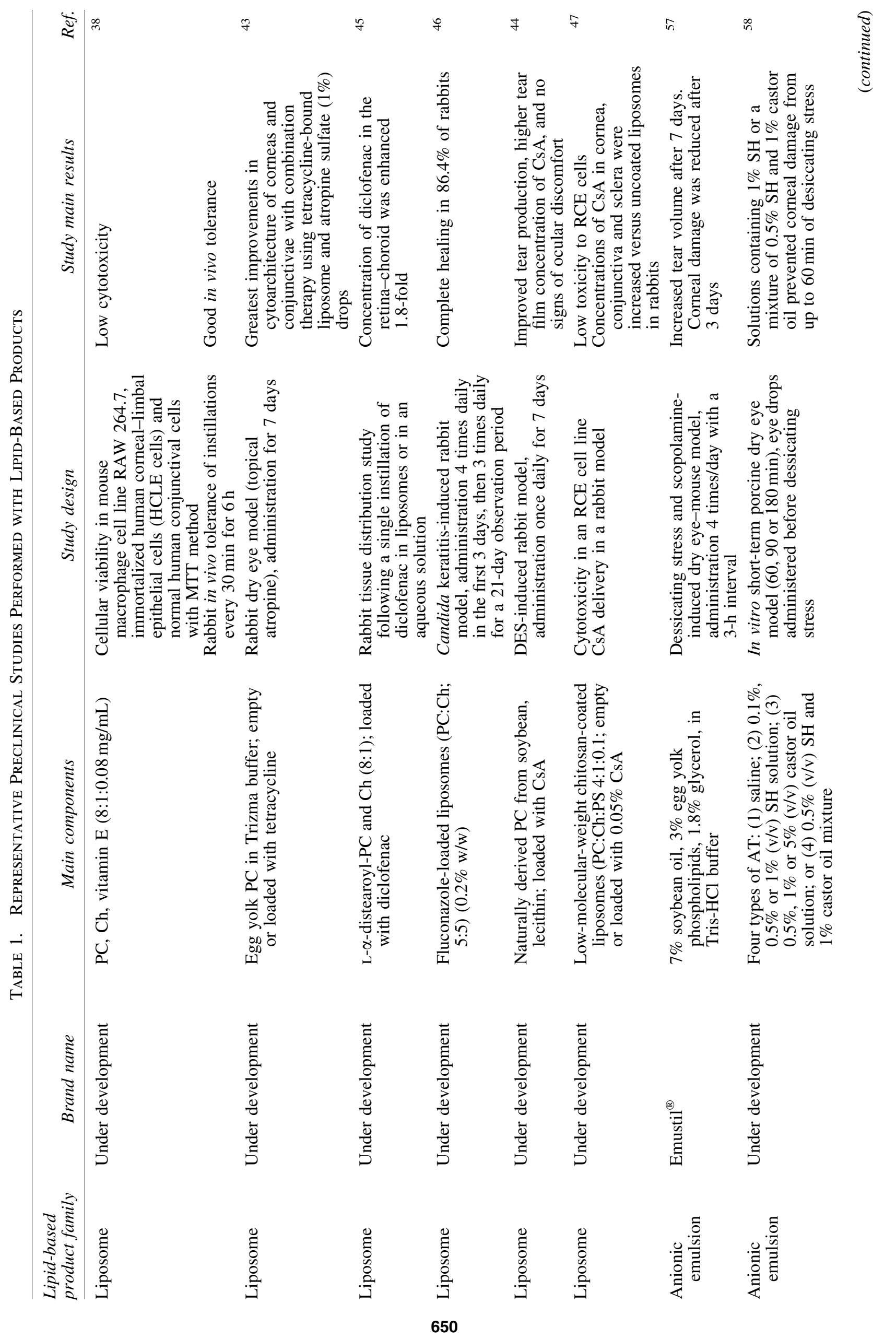




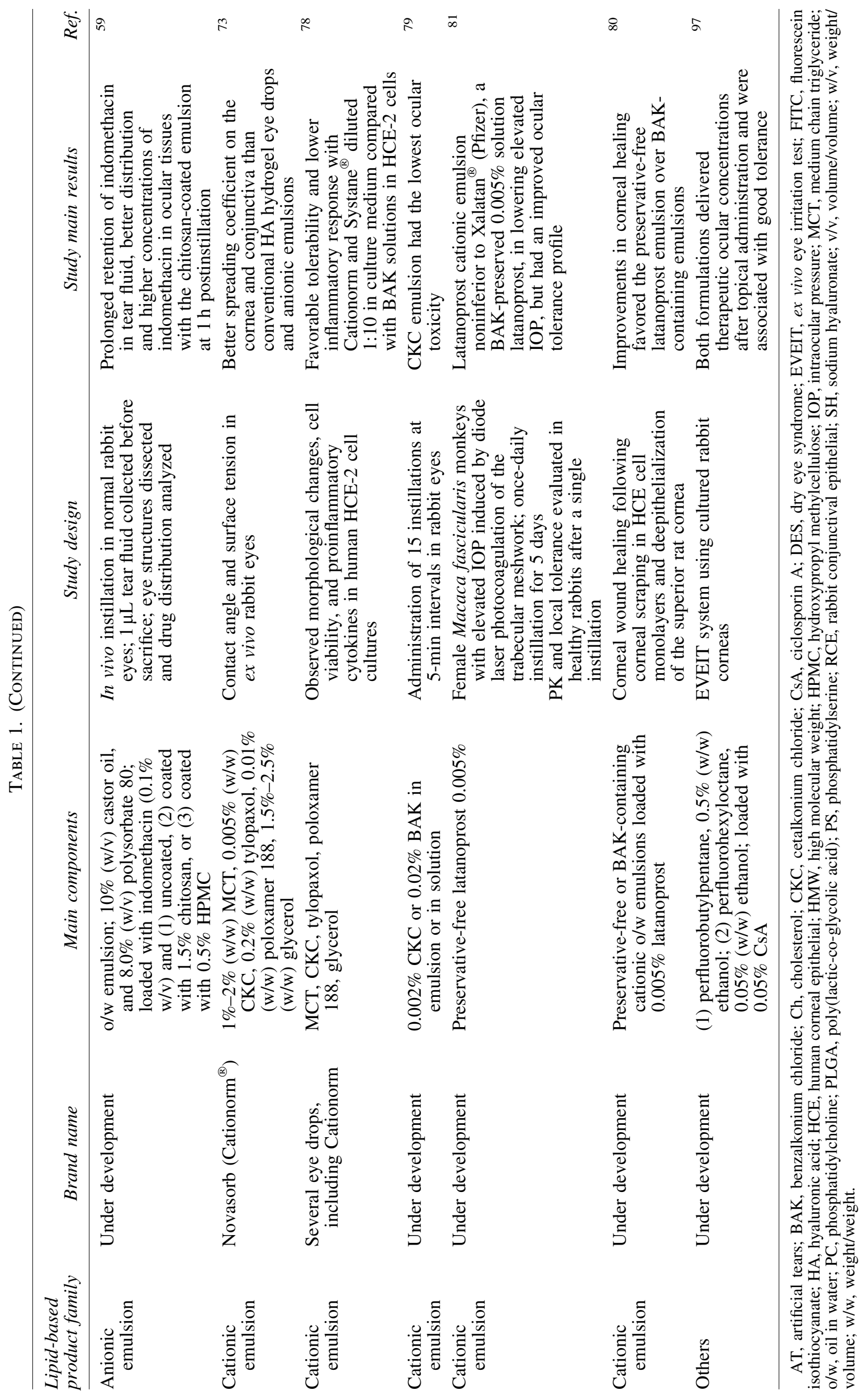




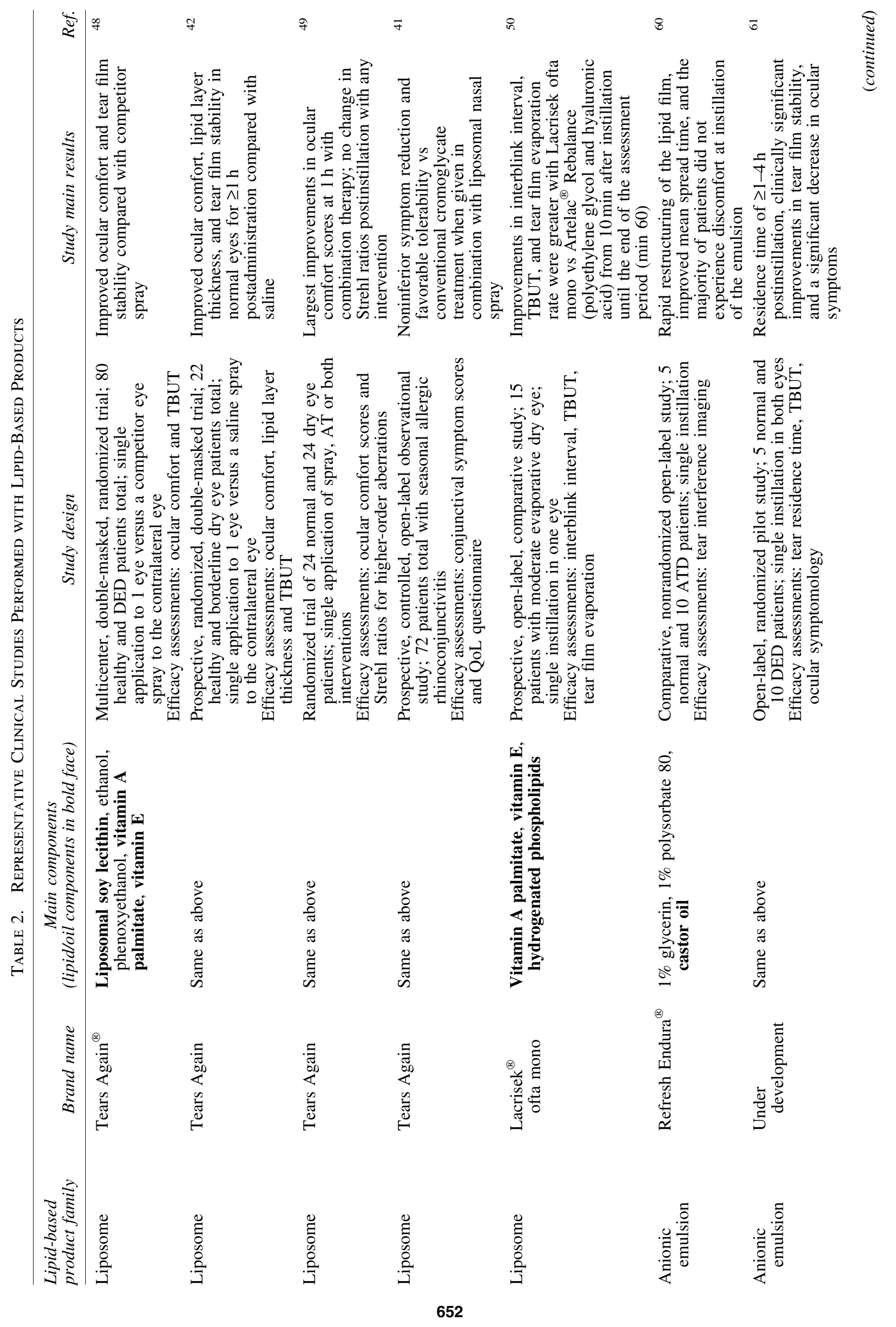




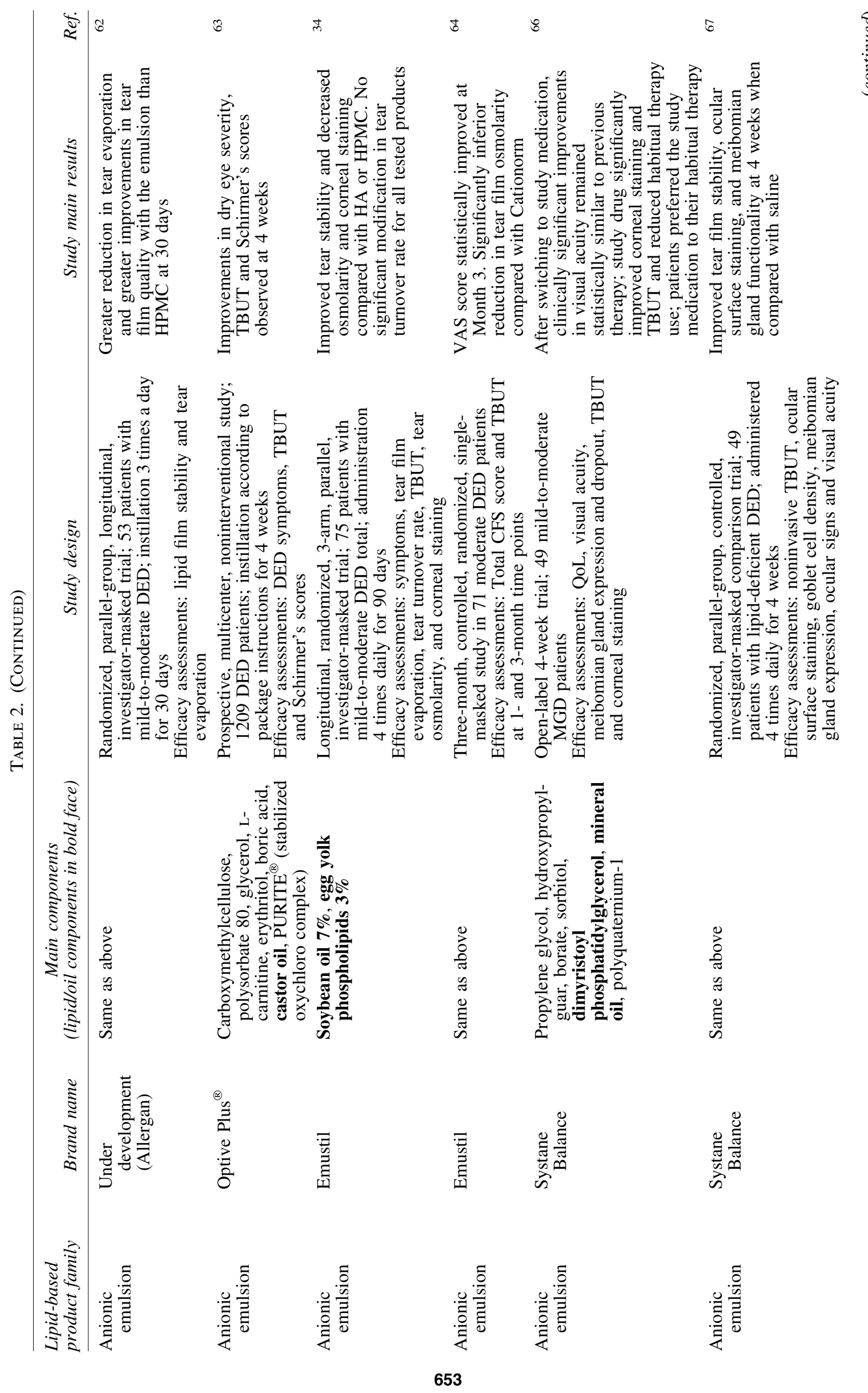




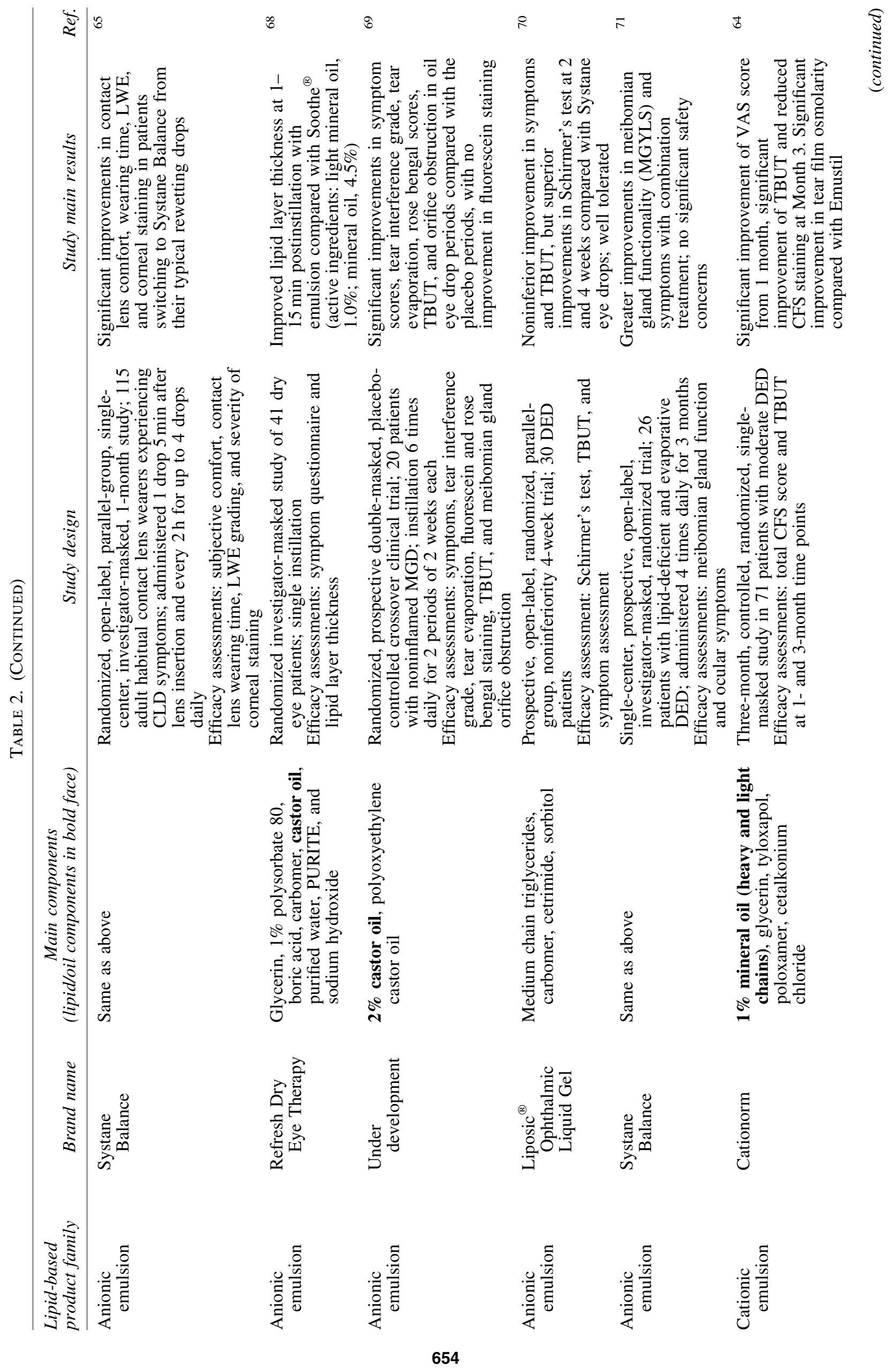




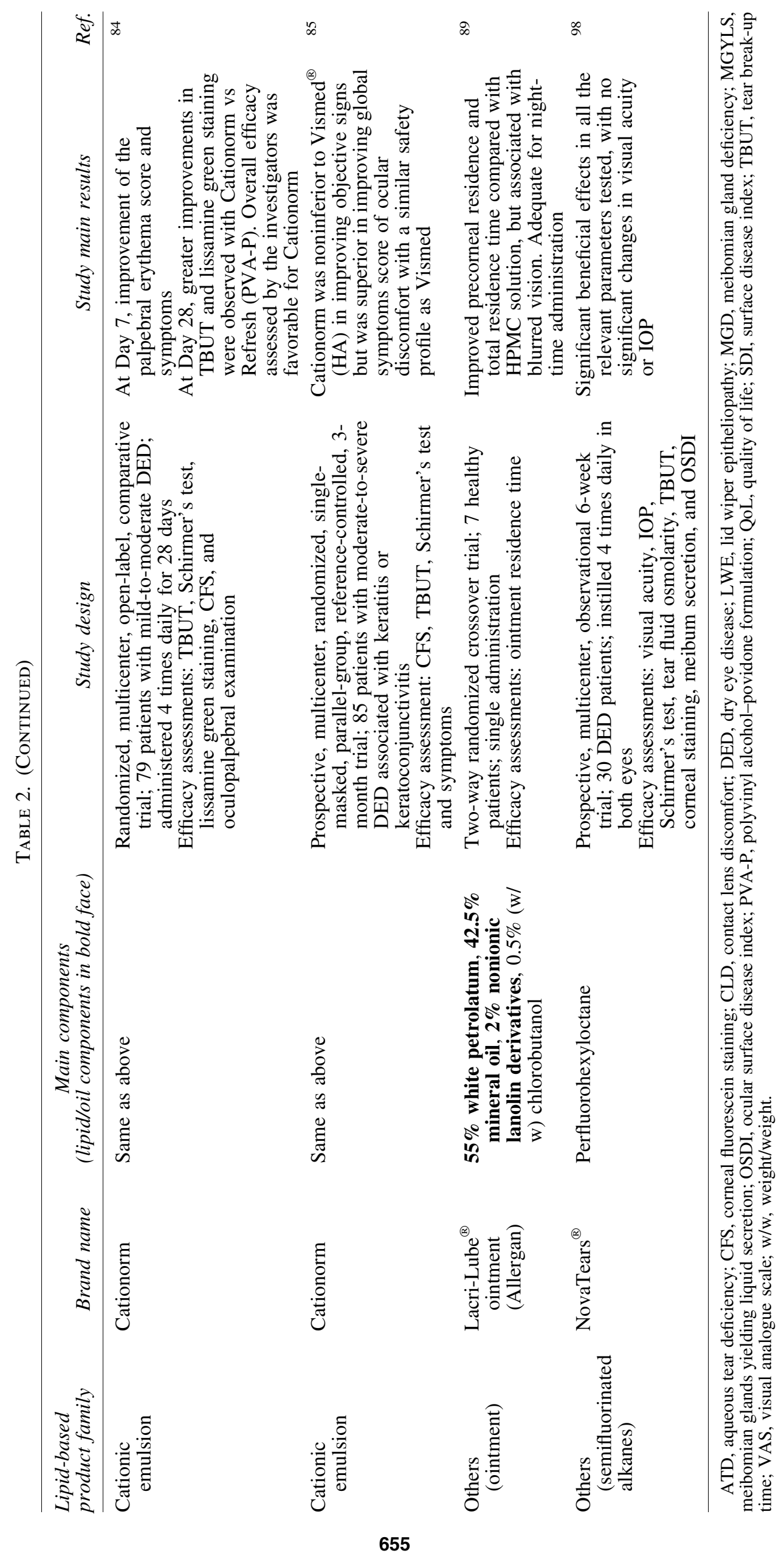




\section{Emulsions}

To better mimic and supplement the tear film, which is also water-based, ${ }^{9,51}$ emulsions containing both water and lipid have been developed. Oil-in-water emulsions consist of oily droplets stabilized by surfactants or emulsifiers dispersed in an aqueous medium (Fig. 1). ${ }^{52}$ For pharmaceutical topical ophthalmic instillation, most emulsions contain submicron-sized particles prepared with oils (eg, sesame oil, castor oil, soya oil, paraffin oil, paraffin light, lanolin, Vaseline $^{\circledR}$ [Unilever], corn oil, glycerin monostearate, medium chain monoglycerides, and medium chain triglycerides) and emulsifiers (eg, phospholipids [Lipoid], polysorbate 80 (Tween ${ }^{\circledR} 80$ ), Cremophor ${ }^{\circledR} \mathrm{RH}$, poloxamer 407 , poloxamer 188, Miranol ${ }^{\circledR} \mathrm{C}_{2} \mathrm{M}$, and tyloxapol) that are well tolerated at the concentrations used in these formulations. ${ }^{53}$ Emulsions can be anionic (negatively charged) or cationic (positively charged) depending on the components added to the formulation during the emulsion process. ${ }^{53}$ Oil-in-water emulsions are often used as topical ocular drug delivery carriers to enhance membrane permeability and cellular uptake of lipophilic molecules. ${ }^{51-55}$

Anionic emulsions. Anionic emulsions are commercially available in some countries and include Optive Plus ${ }^{\circledR}$ (Allergan), Systane ${ }^{\circledR}$ Balance (Alcon), Soothe ${ }^{\circledR}$ XP (Bausch and Lomb), Emustil ${ }^{\circledR}$ (SIFI), Refresh Endura ${ }^{\circledR}$ (Allergan), Restasis $^{\circledR}$ (Allergan), Durezol ${ }^{\circledR}$ (Alcon), Aquarest ${ }^{\circledR} /$ Liposic $^{\circledR}$ (Bausch and Lomb), Soft Santear ${ }^{\circledR}$ (Santen), and Lipimix ${ }^{\circledR}$ (Pharma Stulln). Like liposomes, anionic emulsions have demonstrated a favorable tolerability profile, in that they decrease eye irritation and vision disturbances. For instance, an anionic lipid emulsion of Miglyol $^{\circledR} 840$ oil (IOI Oleo $\mathrm{GmbH})$ and lecithin ${ }^{56}$ tested in rabbits was well tolerated and had a low ocular lesion index after topical instillation $(30 \mu \mathrm{L})$ every $30 \mathrm{~min}$ for $6 \mathrm{~h}$ (Tables 1 and 2). ${ }^{53}$

In terms of efficacy, Emustil (an anionic emulsion containing natural phospholipids) significantly improved tear volume and reduced corneal damage when applied 4 times a day for 7 days either as a monotherapy or in combination with sodium hyaluronate in a mouse model of dry eye. ${ }^{57}$ Artificial tears containing sodium hyaluronate and castor oil tested in a porcine short-term dry eye model also had a protective effect against corneal desiccation. ${ }^{58}$ Similarly, coating emulsions with chitosan was shown to prolong the residence time of the emulsion in the tear fluid of rabbits. ${ }^{59}$

Studies evaluating the efficacy of commercially available anionic emulsions to improve dry eye symptoms and lipid tear film stability in human patients have shown positive results (Table 2). Of note, a pilot study in 5 asymptomatic and 10 symptomatic, aqueous tear-deficient dry eye patients who were given Refresh Endura (castor oil with $1 \%$ glycerin and $1 \%$ polysorbate 80 ) once a day in one eye and saline as control in the other eye demonstrated lipid tear film restructuring after a single instillation of treatment. ${ }^{60}$ Another pilot study in normal and dry eye patients reported increased tear film lipid thickness, tear film breakup time, and comfort scores up to $1 \mathrm{~h}$ postinstillation of Refresh Endura, as well as overall symptom improvement for up to $4 \mathrm{~h}$ postinstillation in patients with symptomatic dry eye. ${ }^{61}$

In patients with mild-to-moderate dry eye treated with an anionic emulsion of $1.25 \%$ castor oil or $0.32 \%$ HPMC monotherapy 3 times daily for 30 days, both treatments resulted in decreased tear evaporation rates, but only the emulsion improved lipid layer structure at day $30 .{ }^{62} \mathrm{~A}$ multicenter observational study evaluated 1,209 dry eye patients for 4 weeks after starting or switching to Optive Plus, which contains carboxymethylcellulose, glycerol, Lcarnitine, erythritol, and a polysorbate 80 vessel that delivers pure castor oil to the tear film. The results indicated improvements in dry eye severity, tear break-up time, and Schirmer's test scores relative to baseline. ${ }^{63}$

Emustil administered 4 times daily for 90 days to evaporative dry eye patients improved tear stability and decreased tear osmolarity and corneal staining to a greater extent than 2 other comparators, Lubristil ${ }^{\circledR} 0.15 \%$ sodium hyaluronate unidose (SIFI) and Dacriosol ${ }^{\circledR} 0.3 \%$ hydroxypropyl methylcellulose unidose (Alcon). ${ }^{34}$ However, a 3-month clinical study comparing Emustil to Cationorm ${ }^{\circledR}$ (Santen) or Optive ${ }^{\circledR}$ (Allergan) in patients with moderate dry eye reported no significant improvement in tear film break-up time or fluorescein staining following treatment with Emustil. ${ }^{64}$

In habitual contact lens wearers experiencing symptoms of contact lens discomfort, Systane Balance (dimyristoyl phosphatidylglycerol, hydroxypropyl-guar, mineral oil, polyoxyl 40 stearate) improved lens comfort, wearing time, lid wiper epitheliopathy, and corneal staining when administered up to 4 times per day versus a nonlipid contact lens rewetting drop. ${ }^{65}$ Systane Balance moderately improved corneal staining and tear film break-up time in patients with dry eye associated with MGD, and approximately $60 \%$ of patients switching to Systane Balance preferred it to their usual lubricant eye drops or artificial tears. ${ }^{66}$

A randomized, parallel-group, controlled, investigatormasked comparison study in patients with lipid-deficient dry eye treated with Systane Balance or saline 4 times daily for 4 weeks showed that Systane Balance restored tear film stability, improved ocular surface staining, and improved meibomian gland functionality. ${ }^{67}$ In addition, dry eye patients treated with either Refresh Dry Eye Therapy ${ }^{\circledR}$ (castor oil with $1 \%$ glycerin and $1 \%$ polysorbate 80 ) or Soothe (light mineral oil 1.0\% and mineral oil $4.5 \%$ ) demonstrated increased lipid layer thickness, but treatment with Soothe resulted in greater improvements in lipid layer thickness. ${ }^{68}$ Castor oil eye drops, another investigational anionic emulsion product, have been well tolerated and have effectively improved symptom scores, tear interference grade, tear evaporation, rose bengal staining, tear film break-up time, and orifice obstruction scores in MGD patients when administered 6 times daily for 2 weeks. ${ }^{69}$

Carbomer-based lipid artificial tears improved both dry eye symptoms and signs, including Schirmer's test values and tear film break-up time, similar to or better than hydroxypropyl (HP)-guar gel after 2 and 4 weeks of treatment. ${ }^{70}$ Furthermore, meibomian gland secretion improved to a greater extent after 3 months of combination therapy with anionic emulsions, lid hygiene, and omega-3 nutritional supplementation versus treatment with only warm and wet compresses in patients with lipid-deficient dry eye. ${ }^{71}$

In the published clinical trials reviewed herein, the most common adverse event related to the application of anionic emulsions observed between studies was blurred vision. $^{60,62,63,66}$ However, in some studies, adverse events were not reported. $^{34,61,67}$ This underlines the safety of their use as ophthalmic drug delivery systems. 
Cationic emulsions. Cationic emulsions are biphasic formulations of positively charged oil nanodroplets (oily phase) dispersed in water (the continuous phase) (Fig. 1, 2b). ${ }^{72,73}$ The positively charged nanodroplets within cationic emulsions interact with the negatively charged ocular surface mucins and cell membranes. ${ }^{51,72,74}$ This bioadhesive property prolongs eye drop residence time and improves the bioavailability of lipophilic drug molecules delivered through these emulsions. ${ }^{53,72,73}$ The physicochemical parameters of a cationic emulsion influence its stability and physiological biocompatibility; for instance, the optimal properties of nanodroplets include a size less than $200 \mathrm{~nm}$, a pH between 5 and 7, and an osmolarity of approximately $270 \mathrm{mOsm} / \mathrm{kg} .{ }^{72}$

Choosing the appropriate cationic agent is also essential. Several agents such as stearylamine, oleylamine, poly(ethylenimine), poly(L-lysine), 1,2-di-(9Z-octadecenoyl)sn-glycero-3-phosphoethanolamine (DOPE), 1,2-di-(9Zoctadecenoyl)-3-trimethylammoniumpropane (DOTAP), and benzalkonium chloride (BAK) derivatives are available, but their use as cationic agents is limited by toxicity, stability, or regulatory issues. These limitations encourage the development of unpreserved ophthalmic preparations. ${ }^{75} \mathrm{Ce}$ talkonium chloride (CKC), a C16 BAK derivative, is the preferred cationic agent in cationic emulsions because it has superior lipophilicity that limits it to the oily phase of the oil-in-water nanoemulsion, thereby minimizing toxicity. ${ }^{72}$

In emulsions, quaternary ammoniums, such as $\mathrm{CKC}$, which are not found in the aqueous phase, are solely used as cationic agents and do not exert detergent activity or preservative action. $^{72,73,76,77}$ Cationic emulsions also provide improved spreading coefficients on the cornea and conjunctiva versus conventional eye drops and anionic emulsions, thereby improving ocular surface wettability. This has been demonstrated by Cationorm (Santen; also known as Retaine ${ }^{\circledR}$ MGD in the US; OCuSOFT ${ }^{\circledR}$ ), a preservative-free cationic emulsion, in contact angle and surface tension studies ${ }^{73}$ (Table 1). Additionally, a cationic emulsion containing a combination of phospholipids (Lipoid E 80), poloxamer 188 (Pluronics F68), and stearylamine as emulsifiers had a favorable tolerability profile when administered (40 single-drop instillations per day for 5 days) to rabbit eyes, despite the potential of stearylamine causing ocular irritation. ${ }^{53}$

In additional preclinical studies, human corneal epithelial cells (HCE-2 cells) were incubated with Cationorm or Systane, each diluted $1: 10$, for up to $30 \mathrm{~min}$. The dilution was used to mimic in vivo conditions, whereas the 30-min exposure time was longer than would be realistically expected in vivo. Neither Cationorm nor Systane were associated with any significant change in HCE-2 cell morphology or viability, and reduced inflammatory responses were elicited versus BAK, suggesting that both products would be better options than BAK for long-term use in DED. ${ }^{78}$ Moreover, cationic emulsions utilizing BAK $(0.02 \%)$ and CKC $(0.002 \%)$ as cationic agents were less toxic than BAK/CKC aqueous solutions at the same concentrations in a severe eye irritation rabbit model (15 instillations at 5 -min intervals). ${ }^{79}$ In this same study, a CKC-containing cationic emulsion caused a similar degree of redness, chemosis, and conjunctiva secretions as the phosphate-buffered saline control. ${ }^{79}$

The tolerability of cationic emulsions was also confirmed with a latanoprost-loaded emulsion in HCE cells, in a rat corneal wound model, and in a rabbit ocular tolerance model. ${ }^{80,81}$ Cationic lipids have also demonstrated the potential for exhibiting both antimicrobial and anti-inflammatory properties. $^{82}$ Glucocorticoid-linked polyamine cationic lipids induce glucocorticoid receptor translocation and display bactericidal activity against several strains of Pseudomonas aeruginosa. ${ }^{82}$ Cationorm reduced stromal inflammatory cell infiltration as determined by in vivo confocal microscopy. ${ }^{83}$

In patients with mild-to-moderate dry eye, instillation of Cationorm ( 1 drop per eye 4 times daily for 28 days) improved tear film break-up time as early as Day 7 and was well tolerated by patients (Table 2) ${ }^{84}$ In this same study, a significant improvement in lissamine green staining was observed after 28 days of treatment, suggesting that this cationic emulsion reinforces the lipid layer, minimizes evaporation, and stabilizes the tear film to protect the ocular surface. ${ }^{84}$ In another clinical trial of Cationorm and Vismed $^{\circledR}$ (TRB Chemedica) in patients with moderate-tosevere dry eye, although both eye drops showed similar safety profiles and efficacy in terms of improvements in objective signs of dry eye, Cationorm was superior in improving the global symptoms score of ocular discomfort. ${ }^{85}$

These cationic emulsions are lipid-based drug nanocarriers and promising new vehicles for ocular drug delivery, for example, delivery of ciclosporin, to treat various ocular surface diseases, including dry eye. ${ }^{73,86}$ Although ciclosporin has potent anti-inflammatory properties and is an established second-line treatment option for dry eye, ocular delivery of ciclosporin is challenging because it is highly lipophilic. ${ }^{23,73}$ Nonetheless, ocular delivery of ciclosporin is enhanced by encapsulating it in a cationic emulsion, increasing its bioavailability and corneal penetration. ${ }^{51,52,87,88}$

In the published clinical trials reviewed here, the most common adverse events related to the application of cationic emulsions were eye pain, instillation site pain, or irritation, and these events were mostly mild in severity. ${ }^{84-86}$ These data show the use of cationic emulsions as ophthalmic drug delivery systems is well tolerated.

\section{Other Lipid-Based Carriers}

Other lipid-based products, including sterile ophthalmic ointments, are used as more conventional lubricants. ${ }^{23}$ These products do not contain water and thus do not directly moisturize the ocular surface or replenish tears, but they can potentially replenish waxes or oils through delivery of white petrolatum, mineral oil, or lanolin. ${ }^{89}$ When used as drug delivery vehicles (eg, for ketorolac, tacrolimus, ciclosporin, gefarnate, etc.), ophthalmic ointments prolong precorneal residence time and sustain drug availability. ${ }^{89-91}$ These types of lubricants have been used for the treatment of DED, but their high viscosity often leads to blurred vision upon application. $^{23,92}$ However, when used at bedtime, ophthalmic ointments provide sustained effect without this uncomfortable side effect. ${ }^{89}$ Pure oily solutions (eg, castor oil, olive oil, corn oil, etc.) are often used in hospital-compounded ophthalmic preparations of various drugs, including ciclosporin. ${ }^{93,94}$ However, the role of their intrinsic properties in supplementing or stabilizing the TFLL is unknown.

There are a number of other lipid-based formulations of drug carriers aside from ointments (Fig. 1, 3a, b). Polyaphrons are lipid-containing carriers with oil droplets in the micron range encapsulated within a water film ${ }^{95}$ that are being investigated as vehicles for ciclosporin delivery to treat DED (EudraCT number: 2015-000937-54). ${ }^{96}$ Ciclosporin has 
also been successfully loaded into biocompatible semifluorinated alkanes, and in an ex vivo corneal model, this carrier provided more effective diffusion of ciclosporin through the corneal barrier than Restasis (Table 1). ${ }^{97}$ Recently, another semifluorinated alkane-based drug delivery carrier (NovaTears ${ }^{\circledR}$ [perfluorohexyloctane]; Novaliq GmbH) has been shown to effectively stabilize the tear film, reduce corneal staining, and improve dry eye symptoms in patients with mild-to-moderate dry eye without impacting visual acuity (Table 2). ${ }^{98}$

Lipid nanocarriers are a class of colloids that includes nanostructured lipid carriers (NLCs), solid lipid nanoparticles (SLNs), and lipid-drug conjugates. Recent studies show that NLCs may be useful for ocular drug delivery given their potential to improve drug penetration owing to increased bioadhesion to the ocular epithelium. ${ }^{99-101}$ SLNs are modified nanoemulsions that substitute the liquid oil phase with a solid lipid core and are typically composed of physiological lipid mixtures of high melting point mono-, di-, and triglycerides and waxes stabilized by surfactants. ${ }^{102}$ Like nanoemulsions, SLNs are biocompatible, physically stable, and capable of carrying drugs, such as ciclosporin and other anti-inflammatory drugs, for the treatment of ocular surface diseases. ${ }^{99,100,102}$ SLNs are internalized by ocular tissues and may improve the bioavailability of encapsulated drugs; ${ }^{100}$ however, their benefit in supplementing the tear film or the compatibility of their high melting point lipids with the TFLL have yet to be explored.

In the published clinical trials reviewed above, the incidence of adverse events following application of semifluorinated alkane drops occurred in few $(<5)$ patients, and there were no serious adverse events reported. However, some patients showed signs of mild-to-moderate hypersensitivity to semifluorinated alkane drops. ${ }^{98}$ Overall, data suggest that oily solutions, SLNs, and NLCs are generally well tolerated.

\section{Conclusion}

Lipid-based therapies (liposomal sprays and emulsion eye drops) are an attractive alternative to water-based artificial tears because they more closely mimic the composition of the tear film. Lipid-based therapies not only relieve patient symptoms immediately after topical administration, but may also directly improve the lipid tear film structure and thickness component in ocular surface disease, resulting in enhanced tear film stability. Furthermore, their composition and rheology may benefit tear film properties and tear film stability. Components in the aqueous phase of the emulsions (eg, osmoprotectants such as glycerin, emulsifiers, or polymers) may also provide additional effect on the ocular surface (eg, lubrication, osmoprotection). Oil-in-water emulsions reduce the signs and symptoms of all types of dry eye, ${ }^{35,62}$ but are particularly recommended for lipid-deficient dry eye patients. ${ }^{63}$ Cationic emulsions provide optimal ocular spreading and residence time with ocular surface benefits to improve DED, especially in MGD patients. ${ }^{73,84}$

The favorable tolerability profile and efficacy of lipidbased therapies in improving both signs and symptoms of dry eye make them a promising therapeutic option in the management of DED. ${ }^{37,73,87,103}$ Lipid-based therapies also have the potential to be combined with conventional ocular surface disease therapies such as lid wipes, omega-3 supplementation, ciclosporin, or diquafosol for disease and symptom management. ${ }^{7,104,105}$ Finally, cationic lipids possess anti-inflammatory properties, ${ }^{82,83,106}$ providing a new perspective of lipid-based therapy for ocular surface inflammation and disease. ${ }^{107}$

Improvements in drug delivery mechanisms may provide patients with a longer duration of symptom relief, improve adherence and compliance, and ultimately improve patient satisfaction. In particular, nanotechnologies such as NLCs and SLNs offer the possibility of a high degree of control over pharmacokinetic variables such as residence time, penetration of ocular tissues, solubility, and rate of release. ${ }^{99}$

The choice and composition of the lipids added to artificial tears, in terms of their polarity and quantity, should be further studied to understand their impact on and potential to improve the TFLL and dry eye symptoms and disease progression. An interdisciplinary approach involving lipidomics, surface chemistry, molecular dynamics, lipid aberrations, rheology, and computational biophysics may address this need. $22,108-112$

\section{Acknowledgments}

The authors wish to thank BioScience Communications and Chameleon Communications International for medical copyediting support. J.M. Holopainen acknowledged support from the Sigrid Juselius Foundation, the State Subsidiary to Helsinki University Hospital, and the Finnish Eye Foundation.

This review was supported by Santen SAS (Evry, France).

\section{Author Disclosure Statement}

J.S. Garrigue and M. Amrane are employees of Santen SAS. M.O. Faure is a consultant for Santen SAS and owner of Scientific Consulting For You. J.M. Holopainen was a medical consultant to Croma Pharma and served on advisory boards for Alcon, Allergan, Santen, and Thea; and L. Tong is a consultant for Alcon, Allergan, Eyelens, Mediworks, and Santen.

\section{References}

1. Gipson, I.K. The ocular surface: the challenge to enable and protect vision: the Friedenwald lecture. Invest. Ophthalmol. Vis. Sci. 48:4391-4398, 2007.

2. Leong, Y.Y., and Tong, L. Barrier function in the ocular surface: from conventional paradigms to new opportunities. Ocul. Surf. 13:103-109, 2015.

3. Zhou, L., and Beuerman, R.W. Tear analysis in ocular surface diseases. Prog. Retin. Eye Res. 31:527-550, 2012.

4. Wolff, E. The muco-cutaneous junction of the lid-margin and the distribution of the tear fluid. Trans. Ophthalmol. Soc. UK. 66:291-308, 1946.

5. Bron, A.J., Tiffany, J.M., Gouveia, S.M., Yokoi, N., and Voon, L.W. Functional aspects of the tear film lipid layer. Exp. Eye Res. 78:347-360, 2004.

6. Zhou, L., Zhao, S.Z., Koh, S.K., et al. In-depth analysis of the human tear proteome. J. Proteomics. 75:3877-3885, 2012.

7. Butovich, I.A., Millar, T.J., and Ham, B.M. Understanding and analyzing meibomian lipids-a review. Curr. Eye Res. 33:405-420, 2008.

8. Dean, A.W., and Glasgow, B.J. Mass spectrometric identification of phospholipids in human tears and tear lipocalin. Invest. Ophthalmol. Vis. Sci. 53:1773-1782, 2012. 
9. Foulks, G.N. The correlation between the tear film lipid layer and dry eye disease. Surv. Ophthalmol. 52:369-374, 2007.

10. Mishima, S., and Maurice, D.M. The oily layer of the tear film and evaporation from the corneal surface. Exp. Eye Res. 1:39-45, 1961.

11. Pucker, A.D., and Haworth, K.M. The presence and significance of polar meibum and tear lipids. Ocul. Surf. 13:26-42, 2015.

12. Millar, T.J., and Schuett, B.S. The real reason for having a meibomian lipid layer covering the outer surface of the tear film-A review. Exp. Eye Res. 137:125-138, 2015.

13. Rantamaki, A.H., Telenius, J., Koivuniemi, A., Vattulainen, I., and Holopainen, J.M. Lessons from the biophysics of interfaces: lung surfactant and tear fluid. Prog. Retin. Eye Res. 30:204-215, 2011.

14. Cwiklik, L. Tear film lipid layer: a molecular level view. Biochim. Biophys. Acta. 1858:2421-2430, 2016.

15. Rantamaki, A.H., Javanainen, M., Vattulainen, I., and Holopainen, J.M. Do lipids retard the evaporation of the tear fluid? Invest. Ophthalmol. Vis. Sci. 53:6442-6447, 2012.

16. Paananen, R.O., Rantamaki, A.H., and Holopainen, J.M. Antievaporative mechanism of wax esters: implications for the function of tear fluid. Langmuir. 30:5897-5902, 2014.

17. Kulovesi, P., Rantamaki, A.H., and Holopainen, J.M. Surface properties of artificial tear film lipid layers: effects of wax esters. Invest. Ophthalmol. Vis. Sci. 55:4448-4454, 2014.

18. Lam, S.M., Tong, L., Duan, X., et al. Extensive characterization of human tear fluid collected using different techniques unravels the presence of novel lipid amphiphiles. J. Lipid Res. 55:289-298, 2014.

19. Prabhasawat, P., and Tseng, S.C. Frequent association of delayed tear clearance in ocular irritation. $\mathrm{Br} . \mathrm{J}$. Ophthalmol. 82:666-675, 1998.

20. DEWS. The definition and classification of dry eye disease: report of the Definition and Classification Subcommittee of the International Dry Eye WorkShop (2007). Ocul. Surf. 5:75-92, 2007.

21. Craig, J.P., and Tomlinson, A. Importance of the lipid layer in human tear film stability and evaporation. Optom. Vis. Sci. 74:8-13, 1997.

22. Yanez-Soto, B., Mannis, M.J., Schwab, I.R., et al. Interfacial phenomena and the ocular surface. Ocul. Surf. 12: 178-201, 2014.

23. DEWS. Management and therapy of dry eye disease: report of the Management and Therapy Subcommittee of the International Dry Eye WorkShop. Ocul. Surf. 5:163-178, 2007.

24. Qiao, J., and Yan, X. Emerging treatment options for meibomian gland dysfunction. Clin. Ophthalmol. 7:17971803, 2013.

25. Maskin, S.L. Intraductal meibomian gland probing relieves symptoms of obstructive meibomian gland dysfunction. Cornea. 29:1145-1152, 2010.

26. Moshirfar, M., Pierson, K., Hanamaikai, K., et al. Artificial tears potpourri: a literature review. Clin. Ophthalmol. 8:1419-1433, 2014.

27. Rieger, G. Lipid-containing eye drops: a step closer to natural tears. Ophthalmologica. 201:206-212, 1990.

28. Yokoi, N., Georgiev, G.A. Tear-film-oriented diagnosis and therapy for dry eye. In: Yokoi, N., ed. Dry Eye Syndrome: Basic and Clinical Perspectives. London: Future Medicine; 2013; p. 96-108.

29. Baudouin, C., Cochener, B., Pisella, P.J., et al. Randomized, phase III study comparing osmoprotective car- boxymethylcellulose with sodium hyaluronate in dry eye disease. Eur. J. Ophthalmol. 22:751-761, 2012.

30. Lee, J.H., Ahn, H.S., Kim, E.K., and Kim, T.I. Efficacy of sodium hyaluronate and carboxymethylcellulose in treating mild to moderate dry eye disease. Cornea. 30:175179, 2011.

31. Xiao, Q., Hu, Y., Chen, F., and Chen, X. A comparative assessment of the efficacy of carbomer gel and carboxymethyl cellulose containing artificial tears in dry eyes. J. Huazhong. Univ. Sci. Technolog. Med. Sci. 28:592-595, 2008.

32. Lin, T., and Gong, L. Sodium hyaluronate eye drops treatment for superficial corneal abrasion caused by mechanical damage: a randomized clinical trial in the People's Republic of China. Drug Des. Devel. Ther. 9: 687-694, 2015.

33. Simmons, P.A., Carlisle-Wilcox, C., and Vehige, J.G. Comparison of novel lipid-based eye drops with aqueous eye drops for dry eye: a multicenter, randomized controlled trial. Clin. Ophthalmol. 9:657-664, 2015.

34. McCann, L.C., Tomlinson, A., Pearce, E.I., and Papa, V. Effectiveness of artificial tears in the management of evaporative dry eye. Cornea. 31:1-5, 2012.

35. Lee, S.Y., and Tong, L. Lipid-containing lubricants for dry eye: a systematic review. Opt. Vis. Sci. 89:1654-1661, 2012.

36. US Food and Drug Administration. CFR - Code of Federal Regulations Title 21. 2015. Available at: https://www .accessdata.fda.gov/scripts/cdrh/cfdocs/cfcfr/CFRsearch .$c f m$ ?CFRPart=312 (accessed September 12, 2017).

37. Mishra, G.P., Bagui, M., Tamboli, V., and Mitra, A.K. Recent applications of liposomes in ophthalmic drug delivery. J. Drug Deliv. 2011:863734, 2011.

38. Vicario-de-la-Torre, M., Benitez-del-Castillo, J.M., Vico, E., et al. Design and characterization of an ocular topical liposomal preparation to replenish the lipids of the tear film. Invest. Ophthalmol. Vis. Sci. 55:7839-7847, 2014.

39. Al-Muhammed, J., Ozer, A.Y., Ercan, M.T., and Hincal, A.A. In-vivo studies on dexamethasone sodium phosphate liposomes. J. Microencapsul. 13:293-306, 1996.

40. Ebrahim, S., Peyman, G.A., and Lee, P.J. Applications of liposomes in ophthalmology. Surv. Ophthalmol. 50:167$182,2005$.

41. Bohm, M., Avgitidou, G., El Hassan, E., and Mosges, R. Liposomes: a new non-pharmacological therapy concept for seasonal-allergic-rhinoconjunctivitis. Eur. Arch. Otorhinolaryngol. 269:495-502, 2012.

42. Craig, J.P., Purslow, C., Murphy, P.J., and Wolffsohn, J.S. Effect of a liposomal spray on the pre-ocular tear film. Cont. Lens Anterior Eye. 33:83-87, 2010.

43. Shafaa, M.W., El Shazly, L.H., El Shazly, A.H., El gohary, A.A., and El hossary, G.G. Efficacy of topically applied liposome-bound tetracycline in the treatment of dry eye model. Vet. Ophthalmol. 14:18-25, 2011.

44. Karn, P.R., Kim, H.D., Kang, H., et al. Supercritical fluidmediated liposomes containing cyclosporin A for the treatment of dry eye syndrome in a rabbit model: comparative study with the conventional cyclosporin A emulsion. Int. J. Nanomed. 9:3791-3800, 2014.

45. Fujisawa, T., Miyai, H., Hironaka, K., et al. Liposomal diclofenac eye drop formulations targeting the retina: formulation stability improvement using surface modification of liposomes. Int. J. Pharm. 436:564-567, 2012.

46. Habib, F.S., Fouad, E.A., Abdel-Rhaman, M.S., and Fathalla, D. Liposomes as an ocular delivery system of 
fluconazole: in-vitro studies. Acta Ophthalmol. 88:901904, 2010.

47. Li, N., Zhuang, C.Y., Wang, M., Sui, C.G., and Pan, W.S. Low molecular weight chitosan-coated liposomes for ocular drug delivery: in vitro and in vivo studies. Drug Deliv. 19:28-35, 2012.

48. Pult, H., Gill, F., and Riede-Pult, B.H. Effect of three different liposomal eye sprays on ocular comfort and tear film. Cont. Lens Anterior Eye. 35:203-207; quiz 243-204, 2012.

49. McGinnigle, S., Eperjesi, F., and Naroo, S.A. A preliminary investigation into the effects of ocular lubricants on higher order aberrations in normal and dry eye subjects. Cont. Lens Anterior Eye. 37:106-110, 2014.

50. Fogagnolo, P., Ottobelli, L., Diguini, M., and Rossetti, L. Short-term efficacy of two lipidic eyedrops in the treatment of evaporative dry eye. Ital. Rev. Ophthalmol. 2:97-105, 2016.

51. Rabinovich-Guilatt, L., Couvreur, P., Lambert, G., and Dubernet, C. Cationic vectors in ocular drug delivery. $J$. Drug Target. 12:623-633, 2004.

52. Souza, J.G., Dias, K., Pereira, T.A., Bernardi, D.S., and Lopez, R.F. Topical delivery of ocular therapeutics: carrier systems and physical methods. J. Pharm. Pharmacol. 66:507-530, 2014.

53. Tamilvanan, S., and Benita, S. The potential of lipid emulsion for ocular delivery of lipophilic drugs. Eur. J. Pharm. Biopharm. 58:357-368, 2004.

54. Gan, L., Wang, J., Jiang, M., et al. Recent advances in topical ophthalmic drug delivery with lipid-based nanocarriers. Drug Discov. Today. 18:290-297, 2013.

55. Marti-Mestres, G., and Nielloud, F. Emulsions in Health care applications-an overview. J. Dispers Sci. Technol. 23:419-439, 2002.

56. Calvo, P., Alonso, M.J., Vila-Jato, J.L., and Robinson, J.R. Improved ocular bioavailability of indomethacin by novel ocular drug carriers. J. Pharm. Pharmacol. 48: 1147-1152, 1996.

57. Scifo, C., Barabino, S., De Pasquale, G., et al. Effects of a new lipid tear substitute in a mouse model of dry eye. Cornea. 29:802-806, 2010.

58. Hasegawa, T., Amako, H., Yamamoto, T., Tazawa, M., and Sakamoto, Y. Corneal-protective effects of an artificial tear containing sodium hyaluronate and castor oil on a porcine short-term dry eye model. J. Vet. Med. Sci. 76: 1219-1224, 2014.

59. Yamaguchi, M., Ueda, K., Isowaki, A., et al. Mucoadhesive properties of chitosan-coated ophthalmic lipid emulsion containing indomethacin in tear fluid. Biologic. Pharm. Bull. 32:1266-1271, 2009.

60. Di Pascuale, M.A., Goto, E., and Tseng, S.C. Sequential changes of lipid tear film after the instillation of a single drop of a new emulsion eye drop in dry eye patients. Ophthalmology. 111:783-791, 2004.

61. Maissa, C., Guillon, M., Simmons, P., and Vehige, J. Effect of castor oil emulsion eyedrops on tear film composition and stability. Cont. Lens Anterior Eye. 33:76-82, 2010.

62. Khanal, S., Tomlinson, A., Pearce, E.I., and Simmons, P.A. Effect of an oil-in-water emulsion on the tear physiology of patients with mild to moderate dry eye. Cornea. 26:175-181, 2007.

63. Kaercher, T., Thelen, U., Brief, G., Morgan-Warren, R.J., and Leaback, R. A prospective, multicenter, noninterventional study of Optive Plus ${ }^{\circledR}$ in the treatment of patients with dry eye: the prolipid study. Clin. Ophthalmol. 8:1147-1155, 2014.
64. Aragona, P., Spinella, R., Rania, L., et al. Assessment of the efficacy of Cationorm ${ }^{\circledR}$ in patients with moderate dry eye compared with Optive ${ }^{\circledR}$ and Emustil ${ }^{\circledR}$ eye drops. Acta. Ophthalmol. 89, 2011.

65. Guthrie, S.E., Jones, L., Blackie, C.A., and Korb, D.R. A comparative study between an oil-in-water emulsion and nonlipid eye drops used for rewetting contact lenses. Eye Contact Lens. 41:373-377, 2015.

66. Sindt, C.W., and Foulks, G.N. Efficacy of an artificial tear emulsion in patients with dry eye associated with meibomian gland dysfunction. Clin. Ophthalmol. 7:17131722, 2013.

67. Aguilar, A.J., Marquez, M.I., Albera, P.A., Tredicce, J.L., and Berra, A. Effects of Systane $\left({ }^{\circledR}\right)$ Balance on noninvasive tear film break-up time in patients with lipid-deficient dry eye. Clin. Ophthalmol. 8:2365-2372, 2014.

68. Scaffidi, R.C., and Korb, D.R. Comparison of the efficacy of two lipid emulsion eyedrops in increasing tear film lipid layer thickness. Eye Contact Lens. 33:38-44, 2007.

69. Goto, E., Shimazaki, J., Monden, Y., et al. Lowconcentration homogenized castor oil eye drops for noninflamed obstructive meibomian gland dysfunction. Ophthalmology. 109:2030-2035, 2002.

70. Wang, T.J., Wang, I.J., Ho, J.D., et al. Comparison of the clinical effects of carbomer-based lipid-containing gel and hydroxypropyl-guar gel artificial tear formulations in patients with dry eye syndrome: a 4-week, prospective, open-label, randomized, parallel-group, noninferiority study. Clin. Therapeut. 32:44-52, 2010.

71. Korb, D.R., Blackie, C.A., Finnemore, V.M., and Douglass, T. Effect of using a combination of lid wipes, eye drops, and omega-3 supplements on meibomian gland functionality in patients with lipid deficient/evaporative dry eye. Cornea. 34:407-412, 2015.

72. Daull, P., Lallemand, F., and Garrigue, J.S. Benefits of cetalkonium chloride cationic oil-in-water nanoemulsions for topical ophthalmic drug delivery. J. Pharm. Pharmacol. 66:531-541, 2014.

73. Lallemand, F., Daull, P., Benita, S., Buggage, R., and Garrigue, J.S. Successfully improving ocular drug delivery using the cationic nanoemulsion, Novasorb. J. Drug Deliv. 2012:604204, 2012.

74. Royle, L., Matthews, E., Corfield, A., et al. Glycan structures of ocular surface mucins in man, rabbit and dog display species differences. Glycoconj. J. 25:763-773, 2008.

75. European Medicines Agency. EMEA Public Statement on Antimicrobial Preservatives in Ophthalmic Preparations for Human Use (EMEA/622721/2009). Available at: www .techtran.co.jp/reportd/emea091208.pdf (accessed September 12, 2017).

76. Kurup, T., Wan, L., and Chan, L. Preservative requirements in emulsions. Pharm. Acta Helv. 67:204-208, 1992.

77. Sznitowska, M., Janicki, S., Dabrowska, E.A., and Gajewska, M. Physicochemical screening of antimicrobial agents as potential preservatives for submicron emulsions. Eur. J. Pharm. Sci. 15:489-495, 2002.

78. Kinnunen, K., Kauppinen, A., Piippo, N., et al. Cationorm shows good tolerability on human HCE-2 corneal epithelial cell cultures. Exp. Eye Res. 120:82-89, 2014.

79. Liang, H., Brignole-Baudouin, F., Rabinovich-Guilatt, L., et al. Reduction of quaternary ammonium-induced ocular surface toxicity by emulsions: an in vivo study in rabbits. Mol. Vis. 14:204-216, 2008.

80. Liang, H., Baudouin, C., Daull, P., et al. In vitro and in vivo evaluation of a preservative-free cationic emulsion 
of latanoprost in corneal wound healing models. Cornea. 31:1319-1329, 2012.

81. Daull, P., Buggage, R., Lambert, G., et al. A comparative study of a preservative-free latanoprost cationic emulsion (Catioprost) and a BAK-preserved latanoprost solution in animal models. J. Ocul. Pharmacol. Ther. 28:515-523, 2012.

82. Myint, M., Bucki, R., Janmey, P.A., and Diamond, S.L. Synthesis and structure-activity relationships of novel cationic lipids with anti-inflammatory and antimicrobial activities. Bioorg. Med. Chem. Lett. 25:2837-2843, 2015.

83. Daull, P., Feraille, L., Elena, P.P., and Garrigue, J.S. Comparison of the anti-inflammatory effects of artificial tears in a rat model of corneal scraping. J. Ocul. Pharmacol. Ther. 32:109-118, 2016.

84. Amrane, M., Creuzot-Garcher, C., Robert, P.Y., et al. Ocular tolerability and efficacy of a cationic emulsion in patients with mild to moderate dry eye disease - A randomised comparative study. J. Fr. Ophtalmol. 37:589-598, 2014.

85. Robert, P.A., Cochener, B., Amrane, M., Ismail, D., Garrigue, J.S., Pisella, P.J., and Baudouin, C. Efficacy and safety of a cationic emulsion in the treatment of signs and symptoms of moderate to severe dry eye disease: a randomized controlled study. Eur. J. Ophthalmol. 26:546-555, 2016.

86. Leonardi, A., Van Setten, G., Amrane, M., et al. Efficacy and safety of $0.1 \%$ cyclosporine A cationic emulsion in the treatment of severe dry eye disease: a multicenter randomized trial. Eur. J. Ophthalmol. 26:287-296, 2016.

87. Pignatello, R., Carbone, C., Puglia, C., et al. Ophthalmic applications of lipid-based drug nanocarriers: an update of research and patenting activity. Therapeut. Deliv. 6:12971318, 2015.

88. Morrison, P.W., and Khutoryanskiy, V.V. Advances in ophthalmic drug delivery. Therapeut. Deliv. 5:1297-1315, 2014.

89. Greaves, J.L., Wilson, C.G., and Birmingham, A.T. Assessment of the precorneal residence of an ophthalmic ointment in healthy subjects. Br. J. Clin. Pharmacol. 35: 188-192, 1993.

90. Ahuja, M., Dhake, A.S., Sharma, S.K., and Majumdar, D.K. Topical ocular delivery of NSAIDs. AAPS J. 10: 229-241, 2008.

91. Malhotra, M., and Majumdar, D.K. In vivo ocular availability of ketorolac following ocular instillations of aqueous, oil, and ointment formulations to normal corneas of rabbits: a technical note. AAPS PharmSciTech. 6:E523526, 2005.

92. Kushwaha, S.K., Saxena, P., and Rai, A. Stimuli sensitive hydrogels for ophthalmic drug delivery: a review. Int. J. Pharm. Invest. 2:54-60, 2012.

93. Benitez del Castillo, J.M., del Aguila, C., Duran, S., Hernandez, J., and Garcia Sanchez, J. Influence of topically applied cyclosporine A in olive oil on corneal epithelium permeability. Cornea. 13:136-140, 1994.

94. Chast, F., Lemare, F., Legeais, J.M., et al. [Cyclosporine $2 \%$ eye drops preparation]. J. Fr. Ophtalmol. 27:567-576, 2004.

95. Molaei, A., and Waters, K.E. Aphron applications-a review of recent and current research. Adv. Colloid Interface Sci. 216:36-54, 2015.

96. EudraCT. A phase II, multicenter, randomized, doublemasked, 4 parallel arms, controlled 6-month trial designed to evaluate the safety and efficacy of PAD ciclosporin (CsA $0.06 \%$ and $0.03 \%$ ) ophthalmic dispersion administered once daily in combination with lubricant therapy and a 3-month post-treatment safety follow-up in moderate to severe dry eye patients. https://eudract.ema.europa.eu/ results-web/index.xhtml

97. Dutescu, R.M., Panfil, C., Merkel, O.M., and Schrage, N. Semifluorinated alkanes as a liquid drug carrier system for topical ocular drug delivery. Eur. J. Pharm. Biopharm. 88:123-128, 2014.

98. Steven, P., Scherer, D., Krosser, S., et al. Semifluorinated alkane eye drops for treatment of dry eye disease-a prospective, multicenter noninterventional study. J. Ocul. Pharmacol. Ther. 31:498-503, 2015.

99. Souto, E.B., Doktorovova, S., Gonzalez-Mira, E., Egea, M.A., and Garcia, M.L. Feasibility of lipid nanoparticles for ocular delivery of anti-inflammatory drugs. Curr. Eye Res. 35:537-552, 2010.

100. Gokce, E.H., Sandri, G., Bonferoni, M.C., et al. Cyclosporine A loaded SLNs: evaluation of cellular uptake and corneal cytotoxicity. Int. J. Pharm. 364:76-86, 2008.

101. del Pozo-Rodriguez, A., Delgado, D., Gascon, A.R., and Solinis, M.A. Lipid nanoparticles as drug/gene delivery systems to the retina. J. Ocul. Pharmacol. Ther. 29:173188, 2013.

102. Wang, Y., Rajala, A., and Rajala, R.V. Lipid nanoparticles for ocular gene delivery. J. Funct. Biomater. 6:379-394, 2015.

103. Puglia, C., Offerta, A., Carbone, C., et al. Lipid nanocarriers (LNC) and their applications in ocular drug delivery. Curr. Med. Chem. 22:1589-1602, 2015.

104. Koh, S. Clinical utility of $3 \%$ diquafosol ophthalmic solution in the treatment of dry eyes. Clin. Ophthalmol. 9:865-872, 2015.

105. Ames, P., and Galor, A. Cyclosporine ophthalmic emulsions for the treatment of dry eye: a review of the clinical evidence. Clin. Invest. 5:267-285, 2015.

106. Filion, M.C., and Phillips, N.C. Anti-inflammatory activity of cationic lipids. Br. J. Pharmacol. 122:551-557, 1997.

107. Lim, A., Wenk, M.R., and Tong, L. Lipid-Based therapy for ocular surface inflammation and disease. Trends Mol. Med. 21:736-748, 2015.

108. Wizert, A., Iskander, D.R., and Cwiklik, L. Organization of lipids in the tear film: a molecular-level view. PloS One. 9:e92461, 2014.

109. Cher, I. Fluids of the ocular surface: concepts, functions and physics. Clin. Exp. Ophthalmol. 40:634-643, 2012.

110. Lam, S.M., Tong, L., Reux, B., et al. Lipidomic analysis of human tear fluid reveals structure-specific lipid alterations in dry eye syndrome. J. Lipid Res. 55:299-306, 2014.

111. Kulovesi, P., Telenius, J., Koivuniemi, A., et al. Molecular organization of the tear fluid lipid layer. Biophys. J. 99:2559-2567, 2010.

112. Kulovesi, P., Telenius, J., Koivuniemi, A., et al. The impact of lipid composition on the stability of the tear fluid lipid layer. Soft Matter. 8:5826-5834, 2012.

Received: April 25, 2017

Accepted: August 15, 2017

Address correspondence to: Dr. Jean-Sébastien Garrigue

Santen SAS

$R \& D$ Innovation Center

1 rue Pierre Fontaine

Evry 91000

France

E-mail: jean-sebastien.garrigue@santen.com 